\title{
The expression status of TRX,AR, and cyclin DI correlates with clinicopathological characteristics and ER status in breast cancer
}

This article was published in the following Dove Press journal:

OncoTargets and Therapy

19 July 2016

Number of times this article has been viewed

\author{
Weisun Huang' \\ Weiwei Nie' \\ Wenwen Zhang ${ }^{2}$ \\ Yanru Wang' \\ Aiyu Zhu' \\ Xiaoxiang Guan ${ }^{1,2}$ \\ 'Department of Medical Oncology, \\ Jinling Hospital, School of Medicine, \\ Southern Medical University, \\ Guangzhou, People's Republic of \\ China; ${ }^{2}$ Department of Medical \\ Oncology, Jinling Hospital, Medical \\ School of Nanjing University, Nanjing, \\ People's Republic of China
}

Background: The ER signaling pathway plays a critical role in breast cancer. ER signaling pathway-related proteins, such as TRX, AR, and cyclin D1, may have an important function in breast cancer. However, the ways that they influence breast cancer development and progression are still unclear.

Patients and methods: A total of 101 Chinese female patients diagnosed with invasive ductal breast adenocarcinoma were retrospectively enrolled in the study. The expression levels of TRX, $\mathrm{AR}$, and cyclin D1 were detected by immunohistochemistry and analyzed via correlation with clinicopathological characteristics and the expression status of ER, PR, and HER2.

Results: The expression status of TRX, AR, and cyclin D1 was not associated with the patient's age, menopausal status, tumor size, or histological differentiation $(P>0.05)$, but was positively correlated with ER and PR $(P<0.001$, respectively). Most $(66 / 76,86.8)$ TRX-positive patients were also HER2-positive $(P=0.003)$. Of AR- or cyclin D1-positive patients, most had relatively earlier I-II tumor stage ( $P=0.005$ and $P=0.047$, respectively) and no metastatic lymph node involvement ( $P=0.008$ and $P=0.005$, respectively).

Conclusion: TRX was found to be positively correlated with ER and PR expression, whereas it was negatively correlated with HER2 expression. In addition, we found that the positive expression of AR and cyclin D1 was correlated with lower TNM stage and fewer metastatic lymph nodes, and it was more common in ER-positive breast cancer than in the basal-like subtype. This may indicate that AR and cyclin D1 are good predictive and prognostic factors and closely interact with ER signaling pathway. Further studies will be necessary to investigate the response and clinical outcomes of treatment targeting TRX, AR, and cyclin D1.

Keywords: thioredoxin, androgen receptor, cyclin D1, breast cancer, immunohistochemistry

\section{Introduction}

In breast cancer, the ER signaling pathway plays a critical role in cancer development and progression. ER expression is associated with the growth of breast tumors, and the lack of ER expression often indicates more aggressive phenotypes. ${ }^{1,2}$ In recent years, increasing numbers of proteins have been proven to be related to the ER signaling pathway. Some of the most important are TRX, AR, and cyclin D1.

TRX was first identified in Escherichia coli as a dithiol hydrogen donor for ribonucleotide reductase and acts as a key molecule in protein redox regulation in cooperation with TRX reductase and nicotinamide adenine dinucleotide phosphate (NADPH). ${ }^{3,4}$ TRX influences tumor proliferation and progression by activating transcription factors such as $\mathrm{AP}-1, \mathrm{NF}-\kappa \mathrm{B}$, and $\mathrm{p} 53$ by redox regulation and by regulating the cell cycle via the ERK1/2cyclin D1 pathway. ${ }^{5-8}$ Recently, TRX was revealed to enhance the transcription activity of
Correspondence: Xiaoxiang Guan Department of Medical Oncology, Jinling Hospital, Southern Medical University, Guangzhou, 210002, People's Republic of China

Email xguan@nju.edu.cn 
ER and influence ER $\alpha$-mediated gene expression. ${ }^{9,10}$ Although increasing numbers of studies have attempted to investigate the mechanism of TRX's influence on breast cancer development, in vivo studies on tissue samples analyzing its prognostic value in patients' clinicopathological features and prognostic factors, such as ER, PR, and HER2, are still scarce.

Although ER $\alpha$ plays an important role in breast cancer, $\mathrm{AR}$ is the most commonly expressed hormone receptor in both invasive and metastatic breast cancers. It was reported that more than $90 \%$ of primary breast tumors express AR. ${ }^{11}$ Immunohistochemical studies demonstrated that AR expression varies among different breast cancer subtypes. ${ }^{11-13} \mathrm{AR}$ and ER $\alpha$ were shown to crosstalk with each other. In the presence of $\mathrm{E}_{2}$, AR can interact with $\mathrm{ER} \alpha \mathrm{LBD}$ and inhibit the transcriptional activity of both receptors. ${ }^{14}$ AR seems to be associated with favorable clinicopathological features and a prognostic factor for better outcome in ER $\alpha$-positive breast cancers. However, its prognostic value in triple-negative breast cancers remains controversial. ${ }^{15-18}$

Cyclin D1 is known to be a key mediator of cell-cycle progression by binding with $\mathrm{CDK} 4 / 6$ and inactivating the $\mathrm{Rb}$ protein. Cyclin D1 is encoded by CCND1 and is overexpressed in $\sim 50 \%$ of breast cancer specimens. ${ }^{19}$ It can rescue growth factor-deprived and antiestrogen-arrested cells from $\mathrm{G}_{1}$ to complete the cell cycle. ${ }^{20}$ Several studies have shown that overexpressed cyclin D1 in breast cancer patients can bind directly to the ERs and propagate the downstream effects of estrogen in a CDK-independent and $\mathrm{Rb}$-independent manner. ${ }^{21}$ Although evidence has shown that cyclin D1 is a good prognostic factor in ER $\alpha$-positive breast cancers, its role in response to antiestrogen treatment seems to be inversed, leading to conflicting results regarding its role in pathogenesis and prognosis. $^{22}$

It is evident that the roles of TRX, AR, and cyclin D1 in breast cancer are still inconsistent and controversial. Moreover, relevant studies based on Chinese patients are scarce. In the current study, we investigated the relationship between the expression of these three proteins and well-known prognostic factors, including clinicopathological details and the status of ER, PR, and HER2 in Chinese patients.

\section{Patients and methods}

\section{Patient cohort}

Between January 2012 and December 2013, we retrospectively enrolled all consecutive female breast cancer patients with a histologically confirmed diagnosis of invasive ductal adenocarcinoma by operation or biopsy treated at Wuxi People's Hospital, Nanjing Medical University ( $n=101)$.
Patients who had received neoadjuvant chemotherapy or other anticancer treatments before operation or biopsy were excluded from the study. The patients' demographics and clinical characteristics, including age, menopausal status, maximal tumor size, histological differentiation, tumor-nodemetastasis (TNM) classification according to the seventh edition Union for International Cancer Control (UICC) cancer staging systems, and lymph node metastasis, were collected. The status of ER and PR was evaluated by immunohistochemistry (IHC), which was performed by the pathology department of our hospital. Nuclear staining of no less than $10 \%$ was determined to represent ER and PR positivity. The expression of HER2 was scored for the intensity and the percentage of cell membrane staining (-, no staining; + , weak partial staining in more than $10 \%$ tumor cells; ++ , moderately complete staining in more than $10 \%$ tumor cells; +++ , strong complete staining in more than $10 \%$ of tumor cells). ${ }^{23}$ HER2 $(++)$ was defined as positive, while both HER2 $(-)$ and HER2 $(+)$ were described as negative. HER2 $(++)$ was additionally assessed by fluorescence in situ hybridization. ${ }^{24}$ Subtypes of breast cancer (luminal A, luminal B, HER2 overexpression, and basal-like) were defined by ER, PR, Ki67, and HER2 status according to the 2013 St Gallen International Expert Consensus. ${ }^{25}$ This study was approved by the Ethics Committee of Wuxi People's Hospital, Nanjing Medical University, and each patient has signed a consent statement.

\section{IHC}

Consecutive 4 um thick formalin-fixed paraffin-embedded sections were prepared for each specimen. Tissue sections stained with hematoxylin-eosin were histologically evaluated for the verification of the diagnosis and eligibility for IHC analysis.

The sections were heated in a $60^{\circ} \mathrm{C}$ incubator for 2 hours, deparaffinized in xylene, hydrated through an alcohol series with a decreasing concentration gradient, and washed with phosphate-buffered saline (PBS) solution ( $\mathrm{pH}=7.4)$ three times. Then, the sections were heated with $10 \mathrm{mM}$ citric acid buffer ( $\mathrm{pH}=6.0$ ) for 5 minutes to retrieve the antigen. When the temperature decreased to room temperature, the sections were washed with PBS three times and immersed in $3 \% \mathrm{H}_{2} \mathrm{O}_{2}$ for 10 minutes to block endogenous peroxidase. To avoid nonspecific binding, 10\% goat serum was added for 10 minutes. Then, anti-TRX rabbit monoclonal antibody (ab133524, 1:1,000; Abcam, Inc., Cambridge, UK), anti-AR rabbit monoclonal antibody (\#5153,1:400, Life Signaling Technology, Inc.), and anti-cyclin D1 rabbit monoclonal antibody (\#2978, 1:50, Life Signaling Technology, Inc.) were used as the primary antibodies for incubation at $4^{\circ} \mathrm{C}$ overnight for staining. 
Then, the sections were washed with PBS three times and incubated with the secondary antibody (Dako Real Envision HRP K5007; Dako Denmark A/S, Glostrup, Denmark) for 30 minutes at room temperature according to the manufacturer's protocol. Next, 3,3'-diaminobenzidine (Dako Real DAB + Chromogen, K5007) was applied for approximately 2 minutes and removed by rinsing with distilled water. Slides were counterstained with hematoxylin.

\section{Evaluation}

Hematoxylin-eosin and IHC slides were independently evaluated and scored by two pathologists who were blinded to the patients' clinical data. Discordant cases were assessed by a third pathologist and a consensus was reached. Expression levels of the three proteins were described as follows: no $<10 \%$ cytoplasmic and/or nuclear tumor cell expression with a moderate to strong intensity of staining was considered TRX-positive; ${ }^{26}$ sections were interpreted as AR-positive when $>10 \%$ of tumor cell nuclei stained positive, ${ }^{18}$ cyclin D1 expression was considered positive when at least $10 \%$ of tumor cells showed nuclear expression of the marker with a moderate to strong intensity of staining. ${ }^{27}$

\section{Statistical analyses}

The $\chi^{2}$ test or Fisher's exact test was used for the analysis of the relationship between the various categories of clinicopathological characteristics and the expression of TRX, AR, and cyclin D1, respectively. Analyses were performed using the Statistical Package for the Social Sciences, SPSS 18.0 for Windows (SPSS Inc., Chicago, IL, USA). A $P$-value $<0.05$ was considered to indicate a statistically significant difference.

\section{Results}

\section{Clinical characteristics}

A total of 101 patients with a mean age of 56.2 years (range from 30 to 85 years) were included in the study. Of all these patients, $38(37.6 \%)$ patients were premenopausal and $63(62.4 \%)$ patients were postmenopausal. There were $32(31.7 \%)$ patients with a pathologically confirmed maximum tumor size of $<2 \mathrm{~cm}$, while $69(68.3 \%)$ patients had a tumor $2 \mathrm{~cm}$ or larger. According to the seventh edition of the UICC cancer staging systems grouping criteria, 86 (85.1\%) patients were stage I-II and 15 (14.9\%) patients were stage III-IV. Most of the patients $(76,75.2 \%)$ had no metastatic lymph nodes. The number of patients with one to three, and no fewer than four metastatic lymph nodes were 13 (12.9\%) and $12(11.9 \%)$, respectively. Among these cases, 76 patients (75.2\%) were ER-positive; 72 (71.3\%) patients were
PR-positive; and 20 patients (19.8\%) were HER2-positive. Regarding breast cancer subtypes, 35 (34.7\%) patients were luminal A; 49 (48.5\%) patients were luminal B; eight (7.9\%) patients were HER2 overexpressing, and nine (8.9\%) patients were basal-like.

\section{TRX expression}

Of 101 cases, 76 patients (75.2\%) were TRX-positive. IHC results showing patients with TRX-positive and TRXnegative expression are presented in Figure $1 \mathrm{~A}$ and $\mathrm{B}$. There was no relationship between TRX expression and age, menopausal status, tumor size, histological differentiation, TNM stage, or metastatic lymph nodes (Table 1). However, TRX expression was positively correlated with ER and PR $(P<0.0001$, respectively). Among 25 TRX-negative patients $(24.8 \%$, Figure $1 \mathrm{~A})$, only one $(4 \%)$ patient was ER-positive, and the vast majority of patients ( $\mathrm{n}=24,96 \%)$ were ER-negative. In 76 TRX-positive patients, 75 patients (98.7\%) were positive for ER expression. Similar situations were found between TRX and PR expression. Namely, 20/25 (80\%) TRX-negative patients were PR-negative, and 67/76 $(88.2 \%)$ TRX-positive patients were PR-positive. Regarding HER2 expression, most $(66 / 76,86.8)$ TRX-positive patients were also HER2-positive ( $P=0.003)$. In different breast cancer subtypes, substantially, all luminal A (30/31, 96.8\%) and luminal B patients $(41 / 49,83.7 \%)$ were TRX-positive, while 7/8 (87.5\%) HER2 overexpressing and all 8/8 (100\%) basallike patients were TRX-negative $(P<0.0001)$.

\section{AR expression}

Eighty-nine (88.12\%) of the 101 patients were AR-positive and $12(11.88 \%)$ patients were AR-negative (Figure 1C, D). Although AR expression was not correlated with age, menopausal status, tumor size, or histological differentiation, it was related to TNM stage and metastatic lymph nodes (Table 2). Of the 89 AR-positive patients, $79(88.8 \%)$ of them had relatively earlier I-II tumor stage $(P=0.005)$. In addition, among these AR-positive patients, most had no metastatic lymph nodes $(n=70,78.7 \%)$. Only 12 patients $(13.5 \%)$ had one to three metastatic lymph nodes and seven patients $(7.9 \%)$ had more than four metastatic lymph nodes $(P=0.008)$.

AR expression was positively correlated with ER and PR expression $(P<0.0001$, respectively). Among 12 ARnegative patients, eleven patients (91.67\%) were ER-negative and nine patients (75\%) were PR-negative. Of all the ARpositive patients, 75 patients $(84.27 \%)$ were ER-positive and 69 patients (77.53\%) were PR-positive. There was no relationship between AR expression and HER2 expression $(P=0.117)$. 

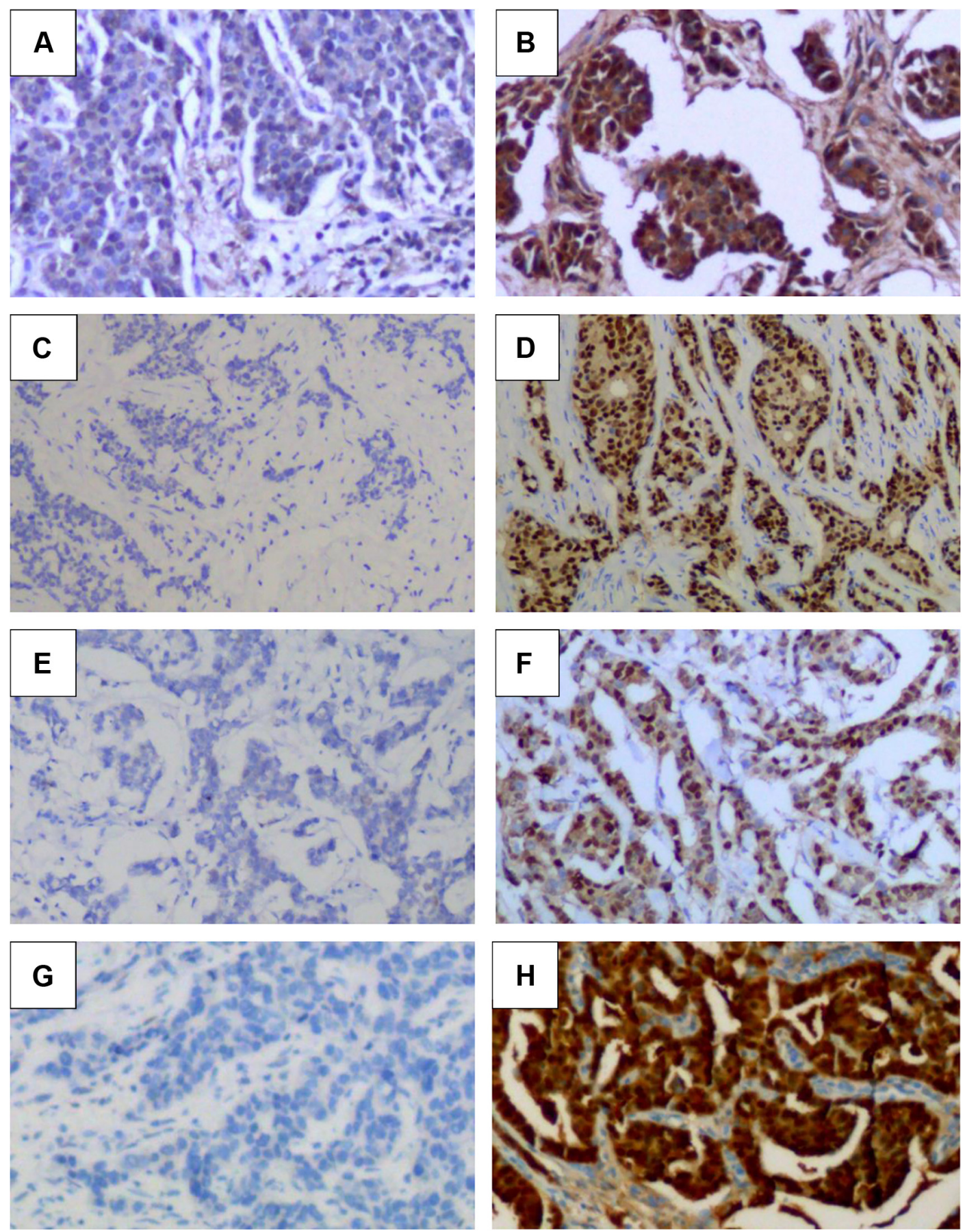

Figure I TRX, AR, cyclin DI, ER expression in breast carcinoma by immunohistochemical staining.

Notes: Low expression of TRX, AR, cyclin DI, and ER in breast tumor (A, C, E and $\mathbf{G})$. High expression of TRX, AR, cyclin DI, and ER in breast tumor (B, D, F and $\mathbf{H})$. Magnification $(400 \times)$.

Inbreastcancersubtypes, all luminal A andHER2-overexpressing patients and most luminal B patients (43/49, 87.76\%) were AR-positive. Additionally, five of the eight basal-like patients were AR-negative $(P<0.0001)$.

\section{Cyclin DI expression}

Most of the breast cancer patients were cyclin D1-positive $(n=80,79.21 \%)$. The results are shown in Figure 1E and $F$.
Similar to AR expression, cyclin D1 expression was not correlated with age, menopausal status, tumor size, or histological differentiation ( $P>0.05$, Table 3$)$. Positive cyclin D1 expression was more common in earlier tumor stages $(P=0.047)$. Of the cyclin D1-negative patients, most $(12 / 21$, $57.14 \%)$ had no metastatic lymph nodes. However, in cyclin D1-positive patients, the majority of patients $(45 / 80$, $56.25 \%)$ had one to three metastatic lymph nodes $(P=0.005)$. 
Table I Correlation between clinicopathological characteristics and TRX expression in I0I breast cancer cases

\begin{tabular}{|c|c|c|c|c|}
\hline \multirow[t]{2}{*}{ Clinicopathological features } & \multicolumn{2}{|c|}{ TRX expression } & \multirow[t]{2}{*}{$\chi^{2}$} & \multirow[t]{2}{*}{$P$-value } \\
\hline & Negative & Positive & & \\
\hline Age (years) & & & 3.628 & 0.057 \\
\hline$\leq 56.2$ & 17 (68.0\%) & 35 (46.5\%) & & \\
\hline$>56.2$ & $8(32.0 \%)$ & $4 \mathrm{l}(53.9 \%)$ & & \\
\hline Menopausal status & & & 0.080 & 0.777 \\
\hline Premenopausal & $10(40.0 \%)$ & $28(36.8 \%)$ & & \\
\hline Postmenopausal & 15 (60.0\%) & $48(63.2 \%)$ & & \\
\hline Tumor size $(\mathrm{cm})$ & & & 0.002 & 0.969 \\
\hline$<2$ & $8(32.0 \%)$ & $24(31.6 \%)$ & & \\
\hline$\geq 2$ & 17 (68.0\%) & $52(68.4 \%)$ & & \\
\hline Histological differentiation & & & 2.537 & 0.111 \\
\hline ॥ & $3(12.0 \%)$ & $21(27.6 \%)$ & & \\
\hline III & $22(88.0 \%)$ & $55(72.4 \%)$ & & \\
\hline TNM stage & & & 0.696 & 0.404 \\
\hline I-II & $20(80.0 \%)$ & $66(86.8 \%)$ & & \\
\hline III-IV & $5(20.0 \%)$ & $10(13.2 \%)$ & & \\
\hline Metastatic lymph nodes & & & 4.444 & 0.117 \\
\hline 0 & 17 (68.0\%) & $59(77.6 \%)$ & & \\
\hline $1-3$ & $2(8.0 \%)$ & II (I4.5\%) & & \\
\hline$\geq 4$ & $6(24.0 \%)$ & $6(7.9 \%)$ & & \\
\hline ER & & & - & 0.000 \\
\hline Negative & 24 (96.0\%) & I (I.3\%) & & \\
\hline Positive & I (4.0\%) & 75 (98.7\%) & & \\
\hline PR & & & 42.695 & 0.000 \\
\hline Negative & $20(80.0 \%)$ & $9(11.8 \%)$ & & \\
\hline Positive & $5(20.0 \%)$ & $67(88.2 \%)$ & & \\
\hline HER2 & & & 8.535 & 0.003 \\
\hline Negative & 15 (60.0\%) & 66 (86.8\%) & & \\
\hline Positive & $10(40.0 \%)$ & $10(13.2 \%)$ & & \\
\hline Subtype ${ }^{a}$ & & & 44.940 & 0.000 \\
\hline Luminal A & I (4.0\%) & 30 (4I.7\%) & & \\
\hline Luminal B & $8(33.3 \%)$ & $4 \mathrm{I}(56.9 \%)$ & & \\
\hline Her-2 overexpression & 7 (29.2\%) & $\mathrm{I}(\mathrm{I} .4 \%)$ & & \\
\hline Basal-like & $8(33.3 \%)$ & - & & \\
\hline
\end{tabular}

Notes: aOne TRX-negative sample and four TRX-positive samples had missing subtype information. “-” indicates no data.

Approximately $68(85 \%)$ and $63(78.75 \%)$ of all the cyclin D1-positive patients were ER- and PR-positive, respectively $(P<0.0001$ and $P=0.001$, respectively). Most luminal A ( $\mathrm{n}=28,90.32 \%)$, luminal $\mathrm{B}(\mathrm{n}=41,83.67 \%)$, and HER2-overexpressing patients $(n=5,62.50 \%)$ were cyclin D1-positive, while more basal-like patients $(\mathrm{n}=6,75 \%)$ were cyclin D1-negative $(P=0.001)$.

\section{Discussion}

Breast cancer is the most common cancer diagnosed in women, and breast tumors are extremely heterogeneous in the gene expression levels between individuals. ${ }^{28}$ The ER signaling pathway plays a pivotal role in breast carcinoma development and progression. Understanding its related proteins, such as TRX, AR, and cyclin D1, provides a new way to distinguish clinical behavior and predict prognosis in patients with morphologically similar tumors. In the present study, we investigated the association between the expression status of TRX, AR, and cyclin D1 and Chinese patients' clinicopathologic data, which included age, menopausal status, maximum tumor size, histological differentiation, TNM stage, lymph node metastasis, and the expression status of ER, PR, and HER2. We found that TRX was associated with ER, PR, and HER2 expression and breast cancer subtypes. Both AR and cyclin D1 were related to TNM stage, lymph node metastasis, the expression of ER and PR, and breast cancer subtypes.

TRX was located in both the cytoplasm and the nucleus to protect cells from oxidative stress. In the nucleus, TRX plays an important role in ensuring proper DNA synthesis and transcription. Cytoplasmic TRXs may act as a reservoir for nuclear TRX. ${ }^{26}$ Therefore, both the nuclear and 
Table 2 Correlation between clinicopathological characteristics and AR expression in I0I breast cancer cases

\begin{tabular}{|c|c|c|c|c|}
\hline \multirow[t]{2}{*}{ Clinicopathological features } & \multicolumn{2}{|c|}{ AR expression } & \multirow[t]{2}{*}{$x^{2}$} & \multirow[t]{2}{*}{$P$-value } \\
\hline & Negative & Positive & & \\
\hline Age (years) & & & 0.256 & 0.613 \\
\hline$\leq 56.2$ & 7 (58.3\%) & $45(50.6 \%)$ & & \\
\hline$>56.2$ & $5(41.7 \%)$ & $44(46.1 \%)$ & & \\
\hline Menopausal status & & & 0.889 & 0.346 \\
\hline Premenopausal & $6(50.0 \%)$ & $32(36.0 \%)$ & & \\
\hline Postmenopausal & $6(50.0 \%)$ & 57 (64.0\%) & & \\
\hline Tumor size $(\mathrm{cm})$ & & & $0.28 I$ & 0.596 \\
\hline$<2$ & $3(25.0 \%)$ & $29(32.6 \%)$ & & \\
\hline$\geq 2$ & $9(75.0 \%)$ & $60(67.4 \%)$ & & \\
\hline Histological differentiation & & & 0 & 0.064 \\
\hline ॥ & 0 & $24(27.6 \%)$ & & \\
\hline III & 12 & $65(72.4 \%)$ & & \\
\hline TNM stage & & & 7.743 & 0.005 \\
\hline I-II & 7 (58.3\%) & 79 (88.8\%) & & \\
\hline III-IV & $5(41.7 \%)$ & 10 (11.2\%) & & \\
\hline Metastatic lymph nodes & & & 8.616 & 0.008 \\
\hline 0 & $6(50.0 \%)$ & $70(78.7 \%)$ & & \\
\hline $1-3$ & I (8.3\%) & $12(13.5 \%)$ & & \\
\hline$\geq 4$ & $5(41.7 \%)$ & 7 (7.9\%) & & \\
\hline ER & & & 32.737 & 0.000 \\
\hline Negative & II (9.2\%) & 14 (I5.7\%) & & \\
\hline Positive & I (8.3\%) & 75 (84.3\%) & & \\
\hline PR & & & 14.254 & 0.000 \\
\hline Negative & $9(75.0 \%)$ & $20(22.5 \%)$ & & \\
\hline Positive & $3(25.0 \%)$ & $69(77.5 \%)$ & & \\
\hline HER2 & & & 0 & 0.117 \\
\hline Negative & 12 & 69 (86.8\%) & & \\
\hline Positive & 0 & $20(13.2 \%)$ & & \\
\hline Subtype ${ }^{a}$ & & & 17.694 & 0.000 \\
\hline Luminal A & 0 & $31(36.5 \%)$ & & \\
\hline Luminal B & $6(54.5 \%)$ & $43(50.6 \%)$ & & \\
\hline Her-2 overexpression & 0 & $8(9.4 \%)$ & & \\
\hline Basal-like & $5(45.5 \%)$ & $3(3.5 \%)$ & & \\
\hline
\end{tabular}

Note: ${ }^{a}$ One AR-negative sample and four AR-positive samples had missing subtype information.

cytoplasmic expression of TRX was considered positive in this assay. Although some previous studies indicated that TRX can accelerate colony formation of breast cancer cells and the knockdown of TRX resulted in significant cell-cycle arrest at the $G_{1}$ phase, other studies suggest that TRX may act as a suppressor of cell proliferation by accelerating the transcription of ER and p53 with the subsequent induction of Ps-2 and p21 expression. ${ }^{8,26,29}$ In this study, TRX expression showed no relationship with tumor size or TNM stage, which indicated that TRX may play a complex role in breast cancer growth. Despite the close relationship between TRX and the ER signaling pathway, some studies have found no correlation between TRX and ER expression. ${ }^{26}$ However, in this assay, we found that TRX expression was not only related to ER and PR expression but also to HER2 expression. TRX tends to be co-expressed with ER and PR, indicating that TRX may activate ER- and ER $\alpha$-mediated gene expression. In addition, major HER2-negative patients were TRXpositive. As far as we know, no report has elucidated the relationship between TRX and HER2 and further study is needed. Most of the luminal A, luminal B, and HER2 patients were TRX-positive while all basal-like patients were TRXnegative in this study. Considering the poorer prognosis of the basal-like subtype, TRX may be a good prognostic factor for breast cancer.

Despite the fact that AR is expressed in the majority of breast cancer tissues, its role in tumor biology and growth remains largely unclear. ${ }^{11}$ Numerous studies have investigated the prognostic value of AR expression in breast cancer. In ER $\alpha$-positive breast cancers, AR is correlated with small tumor size $(<2 \mathrm{~cm})$, reduced lymph node metastasis, lower grade, and a better prognosis for the time to relapse. ${ }^{16,30,31}$ 
Table 3 Correlation between clinicopathological characteristics and cyclin DI expression in I0I breast cancer cases

\begin{tabular}{|c|c|c|c|c|}
\hline \multirow[t]{2}{*}{ Clinicopathological features } & \multicolumn{2}{|c|}{ Cyclin DI expression } & \multirow[t]{2}{*}{$\chi^{2}$} & \multirow[t]{2}{*}{$P$-value } \\
\hline & Negative & Positive & & \\
\hline Age (years) & & & 0.593 & $0.44 I$ \\
\hline$\leq 56.2$ & $8(38.1 \%)$ & 38 (47.5\%) & & \\
\hline$>56.2$ & $13(61.9 \%)$ & $42(52.5 \%)$ & & \\
\hline Menopausal status & & & 1.129 & 0.288 \\
\hline Premenopausal & $10(47.6 \%)$ & $28(35.0 \%)$ & & \\
\hline Postmenopausal & II (52.4\%) & $52(65.0 \%)$ & & \\
\hline Tumor size $(\mathrm{cm})$ & & & 0.119 & 0.731 \\
\hline$<2$ & $6(28.6 \%)$ & $26(32.5 \%)$ & & \\
\hline$\geq 2$ & 15 (7I.4\%) & $54(67.5 \%)$ & & \\
\hline Histological differentiation & & & 1.314 & 0.252 \\
\hline ॥ & $3(14.3 \%)$ & $21(26.3 \%)$ & & \\
\hline III & 18 (85.7\%) & $59(73.7 \%)$ & & \\
\hline TNM stage & & & 3.946 & 0.047 \\
\hline I-II & 15 (7I.4\%) & 71 (88.8\%) & & \\
\hline III-IV & $6(28.6 \%)$ & $9(11.2 \%)$ & & \\
\hline Metastatic lymph nodes & & & 10.320 & 0.005 \\
\hline 0 & $12(57.1 \%)$ & $28(35.0 \%)$ & & \\
\hline $1-3$ & $4(19.0 \%)$ & $45(56.3 \%)$ & & \\
\hline$\geq 4$ & $5(23.9 \%)$ & $7(8.7 \%)$ & & \\
\hline ER & & & 19.648 & 0.000 \\
\hline Negative & $13(61.9 \%)$ & $12(15.0 \%)$ & & \\
\hline Positive & $8(38.1 \%)$ & 68 (85.0\%) & & \\
\hline PR & & & 10.469 & 0.001 \\
\hline Negative & $12(57.1 \%)$ & 17 (2I.3\%) & & \\
\hline Positive & $9(42.9 \%)$ & 63 (78.7\%) & & \\
\hline HER2 & & & 0.268 & 0.605 \\
\hline Negative & 16 (76.2\%) & 65 (8I.3\%) & & \\
\hline Positive & $5(23.8 \%)$ & $15(18.7 \%)$ & & \\
\hline Subtype ${ }^{a}$ & & & 15.228 & 0.001 \\
\hline Luminal A & $3(15.0 \%)$ & $28(36.8 \%)$ & & \\
\hline Luminal B & $8(40.0 \%)$ & $4 \mathrm{l}(53.9 \%)$ & & \\
\hline Her-2 overexpression & $3(15.0 \%)$ & $5(6.6 \%)$ & & \\
\hline Basal-like & $6(30.0 \%)$ & $2(2.7 \%)$ & & \\
\hline
\end{tabular}

Note: ${ }^{a}$ One cyclin DI-negative sample and four cyclin DI-positive samples had missing subtype information.

However, in triple-negative breast cancer, the prognostic value of AR remains unclear. For example, one study found that AR expression was correlated with higher tumor stage and more metastatic lymph nodes. ${ }^{32}$ In contrast, a previous study found that AR expression in triple-negative breast cancer patients indicated fewer metastatic lymph nodes and longer overall survival. ${ }^{33}$ Another study did not detect any significant relationship between $\mathrm{AR}$ expression and relapsefree survival. ${ }^{34}$ In our study, AR status was correlated with lower TNM stage and fewer metastatic lymph nodes in breast cancer. This result was in accordance with previous studies in ER-positive breast cancer. This may be because the majority of the patients $(80.20 \%)$ included in our study were ER-positive. We also detected the co-expression of $A R$ and ER/PR, which further supported the view that AR can increase ER transcriptional activity. ${ }^{35}$ In line with previous studies, we also found a higher AR-positive ratio in ER-positive breast cancer than in basal-like patients. ${ }^{32,36}$

Cyclin D1 is one of the most important target genes that mediates the proliferation of breast cancer cells, which can regulate cells in the proliferative stage of the cell cycle. ${ }^{37}$ Cyclin D1 interacts with CDK4 and CDK6, leading to phosphorylation and thereby inactivating the $\mathrm{Rb}$-protein and its $\mathrm{G}_{1}$-maintaining function, culminating in the expression of proliferation-associated target genes. ${ }^{38}$ Cyclin D1 is also a downstream target of the growth factor and ER signaling pathway and has been identified as a potential marker for breast cancer progression and endocrine responsiveness. ${ }^{39}$ It is overexpressed in more than half of all primary breast cancers, indicating that it may play an important role in tumor development. ${ }^{21}$ A Previous study found that cyclin D1 may be a good prognostic factor in ER $\alpha$-positive breast cancers; 
however, evidence proved that high expression of cyclin D1 leads to resistance to endocrine therapy. In our study, the positive expression of cyclin D1 was correlated with lower TNM stage and fewer metastatic lymph nodes, suggesting that it may be a good prognostic factor. Cyclin D1 expression was associated with ER positivity, consistent with previous studies. ${ }^{40}$ Similar to AR, a higher cyclin D1-positive ratio was also found in ER-positive breast cancer than in basallike patients.

\section{Conclusion}

In conclusion, in the current study, TRX was found to be positively correlated with ER and PR expression and negatively correlated with HER2 expression. In addition, we found that the positive expression of AR and cyclin D1 was correlated with lower TNM stage and fewer metastatic lymph nodes and was more common in ER-positive breast cancer than in the basal-like subtype. This may indicate that AR and cyclin D1 were good predictive and prognostic factors and interacted closely with the ER signaling pathway. Further studies will be necessary to investigate the response and clinical outcomes of treatment targeting TRX, AR, and cyclin D1.

\section{Acknowledgment}

This work was supported by grants from the National Natural Science Foundation of China (number 81272252).

\section{Disclosure}

The authors declare no conflicts of interest.

\section{References}

1. Hulka BS, Chambless LE, Wilkinson WE, Deubner DC, McCarty KS Sr, McCarty KS Jr. Hormonal and personal effects on estrogen receptors in breast cancer. Am J Epidemiol. 1984;119(5):692-704.

2. Ferguson NL, Bell J, Heidel R, et al. Prognostic value of breast cancer subtypes, Ki-67 proliferation index, age, and pathologic tumor characteristics on breast cancer survival in Caucasian women. Breast J. 2013; 19(1):22-30.

3. Laurent TC, Moore EC, Reichard P. Enzymatic synthesis of deoxyribonucleotides. IV. isolation and characterization of thioredoxin, the hydrogen donor from Escherichia coli B. J Biol Chem. 1964;239:3436-3444.

4. Holmgren A. Thioredoxin. Annu Rev Biochem. 1985;54:237-271.

5. Hirota K, Matsui M, Iwata S, Nishiyama A, Mori K, Yodoi J. AP-1 transcriptional activity is regulated by a direct association between thioredoxin and Ref-1. Proc Natl Acad Sci U S A. 1997;94(8):3633-3638.

6. Hirota K, Murata M, Itoh T, Yodoi J, Fukuda K. Redox-sensitive transactivation of epidermal growth factor receptor by tumor necrosis factor confers the NF-kappa B activation. J Biol Chem. 2001;276(28):25953-25958.

7. Jayaraman L, Murthy KG, Zhu C, Curran T, Xanthoudakis S, Prives C. Identification of redox/repair protein Ref-1 as a potent activator of $\mathrm{p} 53$. Genes Dev. 1997;11(5):558-570.

8. Mochizuki M, Kwon YW, Yodoi J, Masutani H. Thioredoxin regulates cell cycle via the ERK1/2-cyclin D1 pathway. Antioxid Redox Signal. 2009;11(12):2957-2971.
9. Hayashi S, Hajiro-Nakanishi K, Makino Y, Eguchi H, Yodoi J, Tanaka H. Functional modulation of estrogen receptor by redox state with reference to thioredoxin as a mediator. Nucleic Acids Res. 1997;25(20): 4035-4040.

10. Rao AK, Ziegler YS, McLeod IX, Yates JR, Nardulli AM. Thioredoxin and thioredoxin reductase influence estrogen receptor alpha-mediated gene expression in human breast cancer cells. $J$ Mol Endocrinol. 2009;43(6):251-261.

11. Parkin DM, Boyd L, Walker LC. 16. The fraction of cancer attributable to lifestyle and environmental factors in the UK in 2010. Br J Cancer. 2011;105 Suppl 2:S77-S81.

12. Loibl S, Muller BM, von Minckwitz G, et al. Androgen receptor expression in primary breast cancer and its predictive and prognostic value in patients treated with neoadjuvant chemotherapy. Breast Cancer Res Treat. 2011;130(2):477-487.

13. Tsang JY, Ni YB, Chan SK, et al. Androgen receptor expression shows distinctive significance in ER positive and negative breast cancers. Ann Surg Oncol. 2014;21(7):2218-2228.

14. Panet-Raymond V, Gottlieb B, Beitel LK, Pinsky L, Trifiro MA. Interactions between androgen and estrogen receptors and the effects on their transactivational properties. Mol Cell Endocrinol. 2000; 167(1-2):139-150.

15. Schippinger W, Regitnig P, Dandachi N, et al. Evaluation of the prognostic significance of androgen receptor expression in metastatic breast cancer. Virchows Arch. 2006;449(1):24-30.

16. Hu R, Dawood S, Holmes MD, et al. Androgen receptor expression and breast cancer survival in postmenopausal women. Clin Cancer Res. 2011; 17(7):1867-1874.

17. Mrklic I, Pogorelic Z, Capkun V, Tomic S. Expression of androgen receptors in triple negative breast carcinomas. Acta Histochem. 2013; 115(4):344-348.

18. Tang D, Xu S, Zhang Q, Zhao W. The expression and clinical significance of the androgen receptor and E-cadherin in triple-negative breast cancer. Med Oncol. 2012;29(2):526-533.

19. Gillett C, Fantl V, Smith R, et al. Amplification and overexpression of cyclin D1 in breast cancer detected by immunohistochemical staining. Cancer Res. 1994;54(7):1812-1817.

20. Musgrove EA, Lee CS, Buckley MF, Sutherland RL. Cyclin D1 induction in breast cancer cells shortens G1 and is sufficient for cells arrested in G1 to complete the cell cycle. Proc Natl Acad Sci U S A. 1994;91(17):8022-8026.

21. Arnold A, Papanikolaou A. Cyclin D1 in breast cancer pathogenesis. $J$ Clin Oncol. 2005;23(18):4215-4224.

22. Kenny FS, Hui R, Musgrove EA, et al. Overexpression of cyclin D1 messenger RNA predicts for poor prognosis in estrogen receptor-positive breast cancer. Clin Cancer Res. 1999;5(8):2069-2076.

23. Xie R, Wang Y, Nie W, et al. Lin28B expression correlates with aggressive clinicopathological characteristics in breast invasive ductal carcinoma. Cancer Biother Radiopharm. 2014;29(5):215-220.

24. Jacobs TW, Gown AM, Yaziji H, Barnes MJ, Schnitt SJ. Specificity of HercepTest in determining HER-2/neu status of breast cancers using the United States Food and Drug Administration-approved scoring system. J Clin Oncol. 1999;17(7):1983-1987.

25. Goldhirsch A, Winer EP, Coates AS, et al. Personalizing the treatment of women with early breast cancer: highlights of the St Gallen International Expert Consensus on the Primary Therapy of Early Breast Cancer 2013. Ann Oncol. 2013;24(9):2206-2223.

26. Matsutani Y, Yamauchi A, Takahashi R, et al. Inverse correlation of thioredoxin expression with estrogen receptor- and p53-dependent tumor growth in breast cancer tissues. Clin Cancer Res. 2001;7(11): $3430-3436$.

27. Joe AK, Memeo L, McKoy J, et al. Cyclin D1 overexpression is associated with estrogen receptor expression in Caucasian but not AfricanAmerican breast cancer. Anticancer Res. 2005;25(1A):273-281.

28. DeSantis CE, Lin CC, Mariotto AB, et al. Cancer treatment and survivorship statistics, 2014. CA Cancer J Clin. 2014;64(4):252-271. 
29. Gallegos A, Gasdaska JR, Taylor CW, et al. Transfection with human thioredoxin increases cell proliferation and a dominant-negative mutant thioredoxin reverses the transformed phenotype of human breast cancer cells. Cancer Res. 1996;56(24):5765-5770.

30. Castellano I, Allia E, Accortanzo V, et al. Androgen receptor expression is a significant prognostic factor in estrogen receptor positive breast cancers. Breast Cancer Res Treat. 2010;124(3):607-617.

31. Park S, Koo JS, Kim MS, et al. Androgen receptor expression is significantly associated with better outcomes in estrogen receptor-positive breast cancers. Ann Oncol. 2011;22(8):1755-1762.

32. McGhan LJ, McCullough AE, Protheroe CA, et al. Androgen receptorpositive triple negative breast cancer: a unique breast cancer subtype. Ann Surg Oncol. 2014;21(2):361-367.

33. He J, Peng R, Yuan Z, et al. Prognostic value of androgen receptor expression in operable triple-negative breast cancer: a retrospective analysis based on a tissue microarray. Med Oncol. 2012;29(2):406-410.

34. Soreide JA, Lea OA, Varhaug JE, Skarstein A, Kvinnsland S. Androgen receptors in operable breast cancer: relation to other steroid hormone receptors, correlations to prognostic factors and predictive value for effect of adjuvant tamoxifen treatment. Eur J Surg Oncol. 1992;18(2): $112-118$.
35. Lanzino M, De Amicis F, McPhaul MJ, Marsico S, Panno ML, Ando S Endogenous coactivator ARA70 interacts with estrogen receptor alpha (ERalpha) and modulates the functional ERalpha/androgen receptor interplay in MCF-7 cells. J Biol Chem. 2005;280(21): 20421-20430.

36. Kuenen-Boumeester V, Van der Kwast TH, Claassen CC, et al. The clinical significance of androgen receptors in breast cancer and their relation to histological and cell biological parameters. Eur J Cancer. 1996;32A(9):1560-1565.

37. Prall OW, Rogan EM, Sutherland RL. Estrogen regulation of cell cycle progression in breast cancer cells. J Steroid Biochem Mol Biol. 1998;65(1-6):169-174.

38. Massague J. G1 cell-cycle control and cancer. Nature. 2004;432(7015): 298-306.

39. Butt AJ, McNeil CM, Musgrove EA, Sutherland RL. Downstream targets of growth factor and oestrogen signalling and endocrine resistance: the potential roles of c-Myc, cyclin D1 and cyclin E. Endocr Relat Cancer. 2005;12 Suppl 1:S47-S59.

40. Utsumi T, Yoshimura N, Maruta M, et al. Correlation of cyclin D1 MRNA levels with clinico-pathological parameters and clinical outcome in human breast carcinomas. Int J Cancer. 2000;89(1):39-43.
OncoTargets and Therapy

\section{Publish your work in this journal}

OncoTargets and Therapy is an international, peer-reviewed, open access journal focusing on the pathological basis of all cancers, potential targets for therapy and treatment protocols employed to improve the management of cancer patients. The journal also focuses on the impact of management programs and new therapeutic agents and protocols on

\section{Dovepress}

patient perspectives such as quality of life, adherence and satisfaction. The manuscript management system is completely online and includes a very quick and fair peer-review system, which is all easy to use. Visit http://www.dovepress.com/testimonials.php to read real quotes from published authors. 